\title{
Adolescentes em medidas socioeducativas em meio aberto e a escola ${ }^{1}$
}

\author{
Roseli Esquerdo Lopes ${ }^{\mathrm{a}}$, Sara Caran Sfair ${ }^{\mathrm{b}}$, Marisa Bittar \\ aProfessora Titular, Departamento de Terapia Ocupacional, Programas de Pós-graduação em Educação e em \\ Terapia Ocupacional, Universidade Federal de São Carlos - UFSCar, São Carlos, SP, Brasil

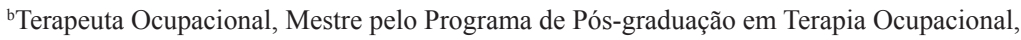 \\ Bolsista CAPES - Coordenação de Aperfeiçoamento de Pessoal de Nível Superior, \\ Universidade Federal de São Carlos - UFSCar, São Carlos, SP, Brasil \\ 'Professora Titular, Departamento de Educação, Programas de Pós-graduação em Educação e em Terapia \\ Ocupacional, Universidade Federal de São Carlos - UFSCar, São Carlos, SP, Brasil
}

\begin{abstract}
Resumo: Este texto é parte de uma pesquisa que buscou a compreensão das proposições do Estatuto da Criança e do Adolescente (ECA) e do papel da escola e de seus agentes sociais, naquilo que se define como medidas socioeducativas aplicáveis aos adolescentes que praticaram ato infracional, tomando-se o caso de uma cidade do estado de São Paulo que tem sido considerada referência nesse campo. Investigou-se quantos e quais eram os adolescentes que estavam em programas de medidas socioeducativas em meio aberto no início de 2006, na referida cidade; detectou-se os equipamentos educacionais que tinham esses adolescentes como seus alunos e, a partir do estudo de caso de um deles, tentou-se apreender como esses adolescentes reconhecem "suas" escolas. Trabalhou-se com diferentes abordagens no que tange à coleta de dados, tanto do âmbito quantitativo quanto qualitativo. Ressalta-se, dentre as conclusões deste estudo, o grande desconhecimento, por parte da direção escolar e dos professores, do cotidiano desses jovens e do próprio ECA. Quanto à cidade, apesar de um sistema de proteção apresentado como modelo nacional, questiona-se o alcance de suas ações naquilo que se refere à articulação da rede de suporte social ao adolescente assistido. Por fim, a escola é uma referência fundamental para os adolescentes em geral e para os de grupos populares em particular, mas estes têm sido discriminados negativamente pela escola. Se frequentar a escola tem importância e se torna obrigatório para o adolescente que cumpre medida socioeducativa, ela tem o dever de superar suas dificuldades para melhor acolhê-los e educá-los.
\end{abstract}

Palavras-chave: Adolescência e Juventude, Educação, Cidadania e Direitos, Políticas Sociais.

\section{Teenagers and socio-educational measures at open environments and at school}

\begin{abstract}
This text is part of a research that aimed to understand the propositions of the Child and Teenager Statute ("Estatuto da Criança e do Adolescente" - ECA) and the role of the school and their social agents in the socio-educational measures applied to teenagers that committed offenses, using as example a city in the State of Sao Paulo that is considered a model in this field. The amount and identity of the teenagers that participated of socio-educational measures in the open system in the beginning of 2006 was investigated in the studied city. The educational facilities where these teenagers were inserted were identified and, through the case study of one of them, an effort was made to learn how they recognize "their" school. Different approaches were used for the quantitative and qualitative data collection. Among the conclusions of this study, the unawareness of the school board and teachers regarding the ECA and these teenagers' daily living was noteworthy. Although the protection system in the studied city is considered a national example, the range of its actions in the network
\end{abstract}

Autor para correspondência: Roseli Esquerdo Lopes, Laboratório METUIA, Departamento de Terapia Ocupacional, Universidade Federal de São Carlos, Rod. Washington Luís, Km 235, CP 676, CEP 13565-905, São Carlos, SP, Brasil, e-mail: relopes@ufscar.br

Recebido em 1/6/2011; $1^{\text {a }}$ Revisão em 11/11/2011; Aceito em 14/12/2011. 
articulation of the social support to the teenager is questioned. Finally, the school is a fundamental reference for most of teenagers and, particularly, for the popular groups, but these groups suffer negative discrimination by the school. If attending school is important and mandatory for teenagers in a socio-educational system, the school must overcome its difficulties to better receive and educate these teenagers.

Keywords: Adolescence and Youth, Education, Citizenship and Rights, Social Policies.

\section{Introdução}

Esta pesquisa problematizou, a partir de uma perspectiva sócio-histórica, o papel, o lugar e a representação da escola para adolescentes e jovens de grupos populares no Brasil, tomando por referência o que dispóe o Estatuto da Criança e do Adolescente (BRASIL, 1990), com relação ao papel da escola e de seus agentes sociais, naquilo que define como medidas socioeducativas aplicáveis aos adolescentes que praticaram ato infracional, numa cidade ${ }^{2}$ do interior do estado de São Paulo, no período de 2006 a 2008.

Para os adolescentes autores de ato infracional, personagens deste estudo, frequentar a escola passa a ser obrigatório e isto está, muitas vezes, previsto na medida socioeducativa que lhes foi aplicada. A partir dessa premissa, busca-se investigar o quanto a escola está preparada para receber esses meninos e meninas e ser um agente efetivo daquilo que prevê o Estatuto da Criança e do Adolescente (ECA). Ainda, como vem se relacionando com esse grupo, de que forma é percebida aquela obrigatoriedade e o desempenho da escola pelos sujeitos sociais em questão, sejam os adolescentes, sejam aqueles responsáveis por estes e pelo cumprimento da medida socioeducativa.

Nessa perspectiva, foram utilizados procedimentos do campo da pesquisa quantitativa e qualitativa, na tentativa de melhor dimensionar os problemas sobre os quais este estudo se debruçou. Assim, foi feito um levantamento sobre quantos e quais eram os adolescentes que estavam em programas de medidas socioeducativas em meio aberto no início de 2006, na cidade pesquisada, detectando-se os equipamentos educacionais em que estavam matriculados e, lançando-se mão do estudo específico de um desses equipamentos ${ }^{3}$, tentou-se apreender como esses adolescentes se reconhecem e reconhecem a sociedade em que vivem, especialmente "suas" escolas.

a) Trabalhou-se com: Dados de um questionário aplicado a todos os estudantes de Ensino Médio da escola em questáo (escola de um bairro periférico da cidade que contava com o segundo maior número de adolescentes cumprindo medidas socioeducativas na cidade, bem próximo da primeira e, na qual, membros da equipe desta pesquisa também atuavam num projeto de extensão universitária, tendo, portanto, a inserçáo requerida nesse tipo de abordagem);

b) Entrevistas que seguiram um roteiro semiestruturado com a direção e coordenação escolar, bem como com representantes de órgãos públicos e de instituiçóes ligadas à problemática do adolescente em conflito com a lei na cidade ${ }^{4}$, para conhecer o que pensam e propóem aqueles que são responsáveis por esses jovens e pelos programas voltados a eles no município;

c) Realização de Oficinas de Atividades e Dinâmicas com adolescentes e jovens na escola em estudo. Foram realizados doze encontros semanais, com três turmas do Ensino Médio, independentemente de terem ou não adolescentes cumprindo medidas socioeducativas. As dinâmicas propostas nos encontros consideravam: o contexto da escola e dos alunos; a vinculação estabelecida com as diferentes turmas; o interesse dos jovens para discutir e participar; o tempo de cada oficina (duração de 50 minutos); e os temas pré-estabelecidos que guiaram as discussóes. Os debates, as discussóes e as dramatizações tiveram como temáticas gerais: - quem eram aqueles adolescentes; - o que pensavam sobre a escola; - o que consideravam como violência; - em quais contextos eles presenciavam violências; - quais tipos de violência encontravam na escola (física, verbal, moral, entre outras classificaçôes); - quem eram os sujeitos envolvidos (vitimadores e vitimizados); - quais as possíveis causas da violência na escola; e - quais seriam as suas proposiçóes para uma escola melhor. Foi possível, também, ouvir esses adolescentes a respeito do que pensam sobre medidas socioeducativas, liberdade assistida, prisóes e 
'FEBEM' - Fundação Estadual do Bem-Estar do Menor ${ }^{5}$. Todas as abordagens foram realizadas por meio do uso de atividades dramáticas, plásticas e lúdicas, o que sensibilizava, favorecia e aguçava a discussão entre os jovens. Ao término das oficinas, foi realizada uma exposição de todo o material confeccionado como síntese do trabalho para toda a comunidade escolar;

d) Encontros e conversas com os adolescentes que, entáo, cumpriam medida socioeducativa e frequentavam a escola foco da pesquisa; tais encontros tinham como diretriz um roteiro de temáticas a serem abordadas.

Essas fontes foram analisadas e discutidas à luz das categorias: cidadania e direitos (BRASIL, 1988; 1990; DULCE, 1997; GOHN, 1994; LOPES; SILVA; MALFITANO, 2006), adolescência e juventude pobre (ABRAMO; BRANCO, 2005; ADORNO, 1991; ARPINI, 2003; REVISTA..., 1997; PILOTTI; RIZZINI, 1995), políticas sociais (CASTEL, 1999; OFFE, 1984) e políticas públicas para a juventude (FREITAS; PAPA, 2003; LOPES; SILVA; MALFITANO, 2006; SPOSITO; CARRANO, 2003).

Do nosso ponto de vista, esse material oferece premissas para a definição de estratégias e caminhos que podem vir a ser utilizados para minorar os problemas escolares dos adolescentes e jovens de grupos populares em geral e daqueles em programas de medidas socioeducativas em meio aberto em particular, de maneira a ampliar suas perspectivas cotidianas e de projetos futuros.

\section{O Estatuto da Criança e do Adolescente e as políticas definidas}

O ECA remete aos municípios a atenção aos problemas com relação às suas crianças e aos seus adolescentes; ainda que existam verbas previstas para a composição dessa atenção tanto do nível federal quanto do estadual, o controle é municipal. É ele quem deve assegurar a rede de suporte necessária para o desenvolvimento integral da criança e do adolescente. $\mathrm{O}$ artigo 86 do Estatuto determina que a

[...] política de atendimento dos direitos da criança e do adolescente far-se-á através de um conjunto articulado de açóes governamentais e não governamentais, da União, dos Estados, do Distrito Federal e dos Municípios." (BRASIL, 1990).
São, então, os governos (municipal, estadual e federal) e a sociedade os responsáveis pela rede de suporte que atende crianças e adolescentes e que deve ser composta por:

- Políticas Sociais Básicas:

[...] direito à vida, à saúde, à alimentação, à educação, ao esporte, ao lazer, à profissionalização, à cultura, à dignidade, ao respeito, à liberdade e à convivência familiar e comunitária. (ECA, art. 4) (BRASIL, 1990).

- Políticas de Garantia de Direitos: mobilização (Fórum de Direitos da Criança e do Adolescente), conselhos (Conselho Municipal dos Direitos da Criança e do Adolescente, Conselho Tutelar) e defesa dos direitos (Vara da Infância e Juventude, Defensoria Pública, Centros de Defesa da Criança e do Adolescente).

- Políticas de Assistência Social: apoio emergencial (cesta básica, albergues, alimentação), programas redistributivos (Renda Mínima, Bolsa Escola, Bolsa Alimentação), geração de trabalho e renda e benefícios permanentes (para aqueles com deficiência, por exemplo).

- Políticas de Proteção Especial: atendimento protetivo (abrigos, educadores de rua, projetos e programas específicos) e atendimento socioeducativo (prestação de serviço comunitário, liberdade assistida, semiliberdade e internação).

A seguir, nos deteremos sobre estas últimas.

\subsection{As políticas de proteção especial}

Esta pesquisa esteve focada nas Políticas de Proteção Especial, especificamente nos atendimentos socioeducativos. O ECA afirma, em seu artigo 98, que "[...] as medidas de proteçáo à criança e ao adolescente são aplicáveis sempre que os direitos reconhecidos nesta lei forem ameaçados ou violados." e, no artigo 100, que

[...] na aplicação das medidas levar-se-ão em conta as necessidades pedagógicas, preferindo-se aquelas que visem ao fortalecimento dos vínculos familiares e comunitários. (BRASIL, 1990).

É, portanto, com base na quebra de direitos básicos e visando ao bem-estar social da criança e do adolescente que o juiz, após a análise do ato infracional, decide a medida a ser aplicada. Como "[...] deve ser considerada a idade do adolescente à data do fato." (ECA, art. 105) (BRASIL, 1990), em casos de terem menos de 12 anos, poderão ser 
encaminhados aos pais, orientados temporariamente, serem obrigados a frequentar um estabelecimento de ensino fundamental, serem incluídos em programas comunitários de apoio, serem encaminhados a abrigos ou colocados em família substituta. Tais medidas também são aplicadas a crianças e adolescentes que sofrerem omissão ou ação que viole seus direitos.

Em caso de ato infracional ocorrido entre 12 e 18 anos (estes últimos, incompletos), o adolescente receberá a medida, que varia de acordo com a gravidade da infração, a capacidade ou não de cumpri-la e as circunstâncias em que foi cometida a infração. Segundo o artigo 112 do ECA (BRASIL, 1990), o adolescente poderá receber: - advertência: verbal, que, em seguida, será escrita e deverá ser assinada; - obrigação de reparar o dano: restituir o objeto ou compensar o prejuízo da vítima; - prestaçáo de serviço à comunidade $^{6}$; - liberdade assistida ${ }^{7}$; - inserção em regime de semiliberdade ${ }^{8}$; - internação em estabelecimento educacional'.

\subsection{A educação segundo o ECA}

O Estatuto traz a garantia legal de escola para todas as crianças e adolescentes, desde o Ensino Infantil (creche, pré-escola), Ensino Fundamental e Ensino Médio. Em seu capítulo IV, artigo 53, refere-se:

A criança e o adolescente têm direito à educação, visando ao pleno desenvolvimento de sua pessoa, preparo para o exercício da cidadania e qualificação para o trabalho, assegurando-se-lhes: I - igualdade de condiçóes para o acesso e permanência na escola; II - direito de ser respeitado por seus educadores; III - direito de contestar critérios avaliativos, podendo recorrer às instâncias escolares superiores; IV - direito de organização e participação em entidades estudantis; V - acesso à escola pública e gratuita próxima de sua residência. Parágrafo único. É direito dos pais ou responsáveis ter ciência do processo pedagógico, bem como participar da definição das propostas educacionais. (BRASIL, 1990).

Assim, todos deveriam receber educação e respeito em suas escolas. Especificamente, com relação aos adolescentes em conflito com a lei em meio aberto, a frequência à escola e seu aproveitamento devem ser supervisionados pelo profissional orientador do programa de liberdade assistida ou de prestaçáo de serviços à comunidade; tal medida teria o objetivo de auxiliar sua ressocialização.

Também se deve investir em sua profissionalizaçáo e inserção no mercado de trabalho. Para os adolescentes cumprindo medida socioeducativa em regime fechado, o artigo 123 do ECA define como obrigatório o oferecimento de atividades pedagógicas em caso de internação, e o artigo 124 , o direito de todos os internos de receber escolarizaçáo e profissionalização.

\section{$3 \mathrm{O}$ adolescente em medida socioeducativa na cidade}

A pesquisa ocorreu em uma cidade de médio porte, com mais de 220.000 habitantes, a qual, segundo o seu então Secretário da Infância e Juventude foi:

\begin{abstract}
[...] uma das primeiras a municipalizar o atendimento da Liberdade Assistida, da Prestação de Serviço à Comunidade. Já em 1993 nós tínhamos uma comissão que discutia a implantação da semiliberdade e, de fato, fomos dos primeiros municipios fora da Capital que [...] instituiu a semiliberdade no municipio e o fez de um modo inovador, com uma entidade privada cuidando, uma entidade particular com uma qualidade diferente do padräo da FEBEM, depois, [...] inovamos também com a criação de um [Serviço Integrado] e, diga-se, no estado de São Paulo foi o primeiro núcleo criado, talvez um dos primeiros no país, aplicando, colocando em prática o artigo 88 no inciso quinto do ECA.
\end{abstract}

Desse modo, a cidade apresentava um serviço considerado modelo de atendimento a adolescentes em medidas socioeducativas, implantado através de um convênio entre a Prefeitura, uma organização católica e a FEBEM.

O referido Serviço Integrado tinha à época uma capacidade para atender 135 adolescentes e oferecia as medidas de prestação de serviço à comunidade, liberdade assistida e semiliberdade.

Conforme o Juiz de Direito da Vara da Infância e Juventude, o adolescente que comete um ato infracional é encaminhado pela polícia ao Serviço Integrado e um técnico da área da assistência social o entrevista, juntamente com seus responsáveis. Tal entrevista auxilia o juiz na decisão da medida mais adequada ao caso. São oferecidas açóes voltadas à saúde, à educação e ao lazer para o jovem e para a sua família e o Serviço Integrado faz o seu acompanhamento com relação ao cumprimento da medida. Um benefício desse modelo é a maior rapidez com que os casos são julgados e a medida é aplicada, o que se dá devido à integração dos órgãos envolvidos (Segurança Pública, Ministério Público, Vara da Infância e Juventude, Assistência Social, Saúde, Educação, FEBEM e a Ordem dos 
Advogados do Brasil), ainda, conforme relato do Juiz de Direito da Vara da Infância e Juventude.

Tal projeto é considerado modelo nacional pelo fato de, segundo seus coordenadores, oferecer o suporte psicológico e social que o jovem necessita, resultando em índices de reincidência avaliados como sendo baixos.

Sendo assim, mesmo que julguem que possam ser feitas modificações importantes na estrutura do projeto, autoridades da cidade e os seus coordenadores relatam que os seus objetivos têm sido atingidos.

\subsection{Adolescentes em medidas socioeducativas em meio aberto e suas escolas: quem são?}

Entre agosto e outubro de 2006, foi realizada a coleta do número de adolescentes cumprindo medida socioeducativa em meio aberto na cidade e verificada a sua situação escolar no que se referia a estar ou não frequentando a escola, bem como qual era essa escola. De um total de 175 adolescentes, 87 (49,7\%) estudavam em diferentes escolas; 81 (46,3\%) não estavam matriculados, mas aguardavam vagas para 2007; e, com relaçáo a 7 deles (4\%), este dado era desconhecido por motivos como transferência de escola e paradeiro ignorado.

Com relação às escolas desses adolescentes, foi possível obter a informaçáo a respeito daquelas frequentadas por 72 deles. Eram 23 estabelecimentos diferentes, 16 públicas e 5 privadas. Dentre as públicas, que abarcavam $90,3 \%$ dos adolescentes, duas se destacaram com mais de $40 \%$ dos casos divididos entre elas. Uma delas foi escolhida para o desenvolvimento deste estudo, por ser uma escola em que já existia uma aproximação da equipe do projeto com o corpo docente e administrativo, além do trabalho com os adolescentes e jovens, feito desde o primeiro semestre de $2006^{10}$.

\subsection{A escola}

A escola estudada localiza-se na periferia da cidade, em uma regiáo considerada violenta por ser próxima a um conjunto de bairros tidos como perigosos. Trata-se, portanto, de uma região estigmatizada pela população do restante da cidade, inclusive pelos professores que nela atuam. Entre 2006 e 2008, ofereceu Ensino Fundamental, Ensino Fundamental em período integral (para o Ciclo II, das 7:00 às 16:20) e noturno, além de Ensino Médio nos períodos matutino e noturno, assim como Educação de Jovens e Adultos (noturno). Atualmente, a parcela de ensino em período integral foi desativada.

No primeiro semestre de 2006, foram realizadas Oficinas de Atividades e Dinâmicas nas quais se trabalhou, com alunos do Ensino Médio, a temática da violência em geral e da violência na escola em particular, sem que se lidasse, especificamente, com o assunto de medidas socioeducativas, embora este tenha sido abordado pelos alunos.

Como ponto de partida, foi aplicado um instrumento estruturado para as cinco turmas do Ensino Médio do período da manhã da escola em questáo, perfazendo o total de 91 questionários respondidos. Dessas turmas, duas eram de primeiro ano, duas de segundo ano e uma de terceiro ano. A partir do envolvimento com essa atividade em cada turma, foram escolhidas três para a realização das oficinas, sendo elas o primeiro ano "A", segundo ano "B" e terceiro ano "A", num total de 62 alunos. Com base nas respostas às questóes sobre violência, foi traçado um plano para a realização das Oficinas na escola. Foram realizados 12 encontros para a discussão dos temas: Violência e Escola.

Essa estratégia foi apresentada, discutida e aprovada pela direção da escola, como também pelos professores nas reuniōes referentes aos HTPCs (Horário de Trabalho Pedagógico Coletivo).

Com os dados coletados nessas Oficinas, foi possível perceber o modo como os jovens em conflito com a lei são vistos por outros jovens, mas náo houve, intencionalmente, aproximação especial com nenhum adolescente em conflito com a lei. Trabalhou-se aqui com diário de campo e o relato minucioso das atividades e de seus resultados.

Concomitantemente às Oficinas, foram realizadas algumas entrevistas para a discussão da situação de violência do bairro e da escola, sendo elas com os professores de História e Português ${ }^{11}$, com o aluno presidente do grêmio estudantil ${ }^{12}$, com a inspetora de alunos e com a coordenadora de ensino ${ }^{13}$.

\subsection{Alguns dados do questionário}

Com relação aos 91 alunos que responderam ao questionário ${ }^{14}$, aplicado no primeiro semestre de 2006, temos:

\subsubsection{Perfil socioeconômico}

Em relação aos bairros onde residem, a grande maioria dos alunos provém de bairros próximos à escola; apenas $12 \%$ vêm de bairros mais distantes. 
Todos os bairros são da periferia da cidade e considerados de grupos econômicos desfavorecidos.

Outro indicador que tomamos para traçar o perfil socioeconômico está relacionado ao número de cômodos e de pessoas nas casas onde residem. A maior parte reside em casas de quatro e de cinco cômodos, com mais quatro ou cinco pessoas; mora pelo menos com a mãe (83 dos 91 questionários respondidos) e o número de adolescentes que residem com ambos os pais é minimamente menor; o número de famílias monoparentais chefiadas pela mãe representa $8 \%$ do total de questionários respondidos.

Setenta e dois por cento dos jovens são de famílias com renda entre um e quatro salários mínimos e mais de 50\% dessas têm entre um e dois salários mínimos.

\subsubsection{A escola}

A média das notas dadas pelos alunos à escola foi de 6,8. A Figura 1 traz a representação gráfica do que os adolescentes pensam sobre a escola.

Como se pode observar, a maior parte considera a escola entre boa e regular e, durante a realização das Oficinas de Atividades e Dinâmicas, percebeu-se que as reclamaçôes superam os elogios, confirmando tal dado. Reclamam, principalmente, da alimentação ruim e insuficiente, de banheiros e pátio sujos, da falta de respeito por parte de professores, direção, coordenação, funcionários e outros alunos e da desorganização administrativa.

Em relação à violência na escola, a grande maioria considera a escola pouco violenta (Figura 2).

Entretanto, pudemos constatar que a violência considerada é a física; a verbal, por exemplo, não é percebida como violência. Este tipo de agressão apareceu enquanto uma queixa de desrespeito de aluno para aluno, professor-aluno e direção-aluno, nas discussóes durante as Oficinas de Atividades e Dinâmicas, e, também, enquanto queixa por parte dos professores e diretores com relação a essas mesmas agressóes verbais, mas somente em raras situaçóes foram consideradas formas de violência.

\subsection{Alguns dados das Oficinas de Atividades}

Foram realizadas 12 oficinas com cada uma das três turmas do Ensino Médio (10 ano "A", $2^{\circ}$ ano "B" e $3^{\circ}$ ano "A", perfazendo um total de 62 alunos participantes) sempre tratando do tema da violência, em suas mais variadas formas. Buscou-se incentivar os jovens a pensarem sobre o modo como participam e se relacionam com fenômenos relacionados à

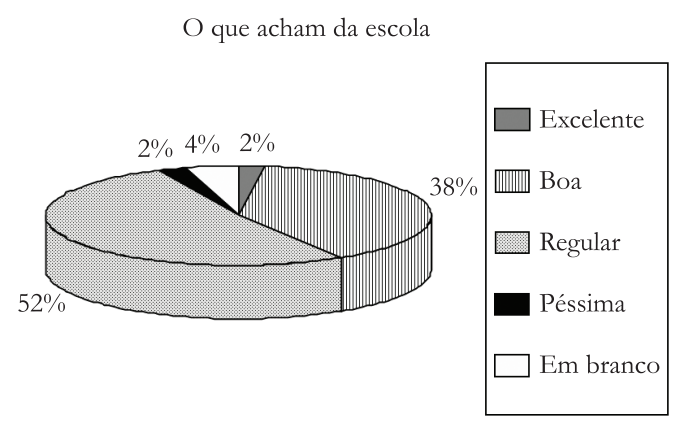

Figura 1. O que os alunos pensam sobre a escola?

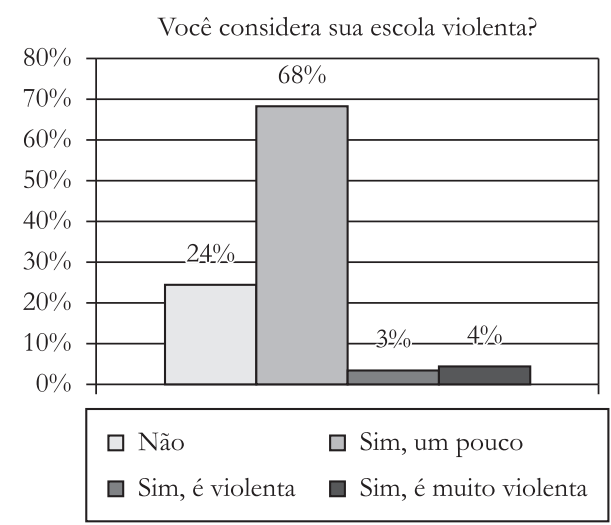

Figura 2. Os alunos consideram a escola violenta?

violência, ouvindo-se suas histórias e opiniōes. Uma das conclusóes que pôde ser constatada logo é que, apesar de a região onde esses adolescentes vivem ser considerada uma das mais violentas da cidade, muitas vezes, trata-se de um dado exagerado, segundo os jovens que participaram do projeto. Relataram situaçóes de preconceito por parte da populaçáo de outros locais da cidade, assim como da polícia, não só pelo bairro onde vivem, mas, também, pelo modo como se vestem.

Frequentemente, a violência aparecia ligada ao consumo e ao comércio de drogas ilícitas e raros eram os jovens que não conheciam alguém que estivesse cumprindo algum tipo de pena; em vários casos tratava-se de outros jovens, irmãos ou primos, na maioria das vezes. Desse modo, falavam com conhecimento de causa sobre o sistema judiciário que enfrentam com suas famílias, tanto o voltado para a população adulta quanto para os adolescentes. Em algumas situações, buscaram justificar atos violentos e/ou infracionais com as situaçóes de vulnerabilidade em que muitos vivem, presenciam ou sabem que o autor de determinado crime vive ou viveu (como fome, habitação precária e falta de recursos mínimos). 
Especificamente, com relação à FEBEM, os adolescentes não a viam como um local adequado para quem comete um crime (ato infracional), por ser considerado desumano e por náo oferecer realmente uma forma efetiva de reabilitação. Entretanto, o Serviço Integrado da cidade também não foi considerado uma solução, pois, "[...] os meninos vão pro Serviço e nada também acontece, só passam a mão na cabeça deles, ninguém sai bom de lá".

$\mathrm{Na}$ manifestação desses jovens, percebe-se o quanto não acreditam que a violência tem solução ou que alguém que comete um ato infracional pode não cometê-lo novamente. Todos têm alguma história de violência ou conhecem algum autor de ato infracional, quando não são eles próprios vítimas e/ou autores. Neste ponto, emerge uma significativa repulsa pela polícia, como uma entidade que, no lugar de protegê-los, está presente, inclusive no interior da escola, para agredi-los, física e moralmente, e mantê-los calados. Segundo relatos, a polícia conheceria cada passo daqueles que ela considera um perigo à sociedade. Várias situaçóes de abuso de poder e violência física foram relatadas e a opiniáo de que a polícia de nada serve é a de grande parte dos adolescentes.

Durante o segundo semestre de 2006, foram realizadas Oficinas de Atividades e Dinâmicas com o Ensino Fundamental, especificamente, com cinco turmas de quintas séries e uma de sexta série. Foram discutidos os temas violência, drogas, sexualidade e protagonismo juvenil. Durante essas atividades, pudemos entrar em contato com a faixa etária mais presente no Programa de Medidas Socioeducativas, no que tange a essa escola.

Apesar da diferença etária, as constataçóes náo diferem muito daquelas observadas durante o primeiro semestre. A repulsa à polícia e a opinião de que o Serviço Integrado da cidade e a FEBEM não ajudam na reinserção social de adolescentes em conflito com a lei apareceram igualmente. As diferenças surgiram quando falamos sobre a escola: os mais jovens apontavam os mesmos problemas (falta de respeito de professores e direção, merenda ruim, sujeira nos pátios e banheiros), mas mostravam-se mais otimistas com relação a possíveis melhoras e acreditavam poder ajudar a modificar a situação, ainda que não soubessem como. Também reclamavam de puniçóes injustas e de exagero por parte, principalmente, da coordenação da escola; não obstante, acreditavam que esta seria a única forma possível para se manter uma certa ordem no local.

Durante todo o período deste estudo, nas atividades de pesquisa e extensão que lá realizamos, especialmente nas Oficinas, não foram verificados atos de violência por parte dos adolescentes que justificassem a "fama" atribuída à instituição (tal como a região onde se insere, a Escola é tida, no senso comum da cidade, como violenta e perigosa, a ser evitada). $O$ fato de residirem nessa região marca suas vidas e coloca suas atitudes em um contexto de dificuldades, de faltas de alternativas, de destino, total ou parcialmente, traçado.

$\mathrm{Na}$ visão da maioria dos trabalhadores da escola, o caminho que parece natural a esses jovens é o do 'desvio' e/ou do 'crime' devido à baixa escolarização e ao nível socioeconômico dos bairros próximos.

A direção da escola mudou três vezes no período da pesquisa, ficando, por um curto espaço de tempo, de náo mais de um mês, vago o cargo de direção e, segundo relatos de alunos e professores, a mudança era frequente. Ainda, conforme tais relatos, isso enfraquece a autoridade da escola, o que justificaria a coordenação a responsabilizar-se pelo que deveria ser tarefa da direção.

A entấo coordenadora ocupava o cargo desde 2000 e era vista como a pessoa a quem os alunos respeitavam na escola. No nosso contato com ela, no cotidiano da escola e na entrevista, referia acreditar que deveria assumir o papel de máe dos alunos e que estes a viam como tal.

Para os alunos, a escola, na pessoa da coordenadora, criava regras desnecessárias ou sem razóes claras; concomitantemente, entretanto, acreditavam que fossem necessárias para o bom andamento do local. Muitos relataram não gostar da coordenadora, mas, por outro lado, afirmavam que sem ela a escola não se sustentaria.

A direção e a coordenação da escola mostraram-se abertas ao nosso trabalho no primeiro semestre, mas no momento de sua avaliação, sugeriram o direcionamento das Oficinas para as quintas séries, consideradas mais 'violentas'; com base nisto, parte de nossas atividades na escola, no segundo semestre de 2006 (conforme já descrito), foi direcionada para pré-adolescentes e adolescentes dessa faixa etária, sem que, no entanto, houvesse modificaçóes nas atitudes dos professores com relação à discussão do fenômeno da violência na escola; em meados do segundo período letivo, quando voltamos a discutir com eles a questão, transferiram para as sextas e sétimas séries a responsabilidade pela falta de disciplina na escola. Percebemos que um dos fatores que levavam os alunos a agirem indisciplinadamente era o desinteresse pelas aulas e o cansaço devido ao longo período em que ficavam na escola, enquanto professores, direção e coordenação atribuíam à idade, à situação socioeconômica e a uma provável situação familiar 
(denominada como "desestruturada") as razôes por atitudes que infringem regras da instituição.

\subsection{Adolescentes em medidas socioeducativas em meio aberto: $o$ que nos dizem alguns deles}

Em setembro de 2006, nos foi passada a informação de que 13 adolescentes da escola em questão cumpriam medidas socioeducativas em meio aberto. Todavia, apesar de nossos esforços, apenas em meados de janeiro de 2007 conseguimos que a Coordenação do Programa de Medidas Socioeducativas em Meio Aberto nos informasse o nome e o endereço (três deles errados) de somente sete adolescentes. Durante os meses de janeiro e fevereiro, esses meninos e meninas foram procurados por nós e realizamos encontros e entrevistas com quatro deles. Outras duas adolescentes com as quais nos encontramos, e que foram ouvidas, não constavam da lista inicial que nos foi entregue pelos responsáveis pelo Programa de Medidas Socioeducativas em Meio Aberto (nós sabíamos de sua situação pelo contato mantido com elas na escola). Uma delas era uma menina que foi transferida para outra escola. Essa garota, no entanto, não frequentava as aulas, argumentando que só aceitava estudar naquela escola e, por isso, passava as manhãs no entorno da instituição.

Temos, então, o depoimento dos seguintes adolescentes: M.A.M.P., 15 anos, $5^{a}$. série do período noturno; M.J.S.S., 14 anos, 6a . série, não estudando naquele momento; J.L.B., 13 anos, $7^{\text {a }}$. série integral; B.G.P., 14 anos, $8^{\text {a }}$. série integral; M.S.S., 15 anos, $8^{\mathrm{a}}$. série integral; D.A.S.B., 17 anos, $7^{\mathrm{a}}$. série do período noturno. Tais dados nos permitem constatar que três dos entrevistados estão em séries que não correspondem à idade.

A seguir, apresentamos um perfil do que pensam esses meninos e meninas acerca de diferentes temas sobre os quais conversamos em diversos encontros durante o verão de 2007.

\subsection{Trabalho}

Cinco entrevistados relataram nunca terem trabalhado, apenas D., que fora despedido recentemente. Ele era, também, o único que demonstrava alguma vontade de voltar a trabalhar, pois achava que "é bom ganhar um dinheirinho, não deu mais, mas eu gostava." Entretanto, nenhum dos entrevistados planejava ter algum trabalho, ainda que
J. e B. desejassem fazer algo importante ou bom no futuro, sem especificar o quê.

\subsection{Escola}

Apesar das críticas ouvidas durante as Oficinas, os entrevistados relataram que a escola é boa e que está cumprindo seu papel para que tenham um bom futuro. Apenas M.A. considerou que a escola era ruim e não estava ajudando na realização de seus planos; ao ser questionado sobre o porquê disso, afirmou que "falta um monte de coisas", sem conseguir apontar algo mais específico. Para B. a escola "ainda não ajudou (em seu futuro), mas vamos ver mais pra frente".

Três entrevistados mostraram-se mais convictos no trabalho da escola e em sua importância para o futuro deles. Percebe-se em suas falas a reprodução de frases comuns no dia a dia de todos nós, como que "sem a escola nós não é nada, né?" (B.) e "sem ler e escrever a gente não é ninguém, né? Não consegue nada" (D.), o que contradiz com a atitude de não assistirem às aulas, com algumas 'falas' em outros momentos e até com o fato de pararem de estudar, demonstrando que náo estão satisfeitos com o ensino e que não sentem realmente que fará falta para o futuro. Tal postura confirma o fato de que atualmente existe um discurso sobre educação que é considerado pela sociedade em geral importante de ser reproduzido, o que é feito repetidamente sem reflexão, especialmente em casos como o que estamos analisando. Ou seja, quando se pergunta a alguém sua opinião sobre a educação, a pessoa indagada já sabe o que deve responder: são as frases feitas, clichês.

Outra manifestação comumente encontrada entre os jovens diz respeito ao valor instrumental ou simplesmente mais prático da educação, seja para o trabalho seja para obter êxito em graus subsequentes da trajetória escolar. Dificilmente recebemos uma resposta sobre o valor da educação como formação humana, como meio de humanizar cada vez mais a pessoa, ou seja, o seu valor intrínseco não faz parte do rol de estereótipos normalmente verbalizados em situaçóes como essas. Nessa perspectiva, é ilustrativo o depoimento a seguir de J., que se mostrou mais otimista, inclusive justificando o porquê disso:

[...] as aulas também, a gente tem curso de espanhol agora, tem aqui na escola, e vai mudar muito pra mim, porque eu tendo uma aula de espanhol, no men futuro eu vou saber, pra eu passar no vestibular eu vou saber o espanhol, eu não vou precisar pagar todo mês duzentos, trezentos, $e$ assim, às vezes eu posso até arrumar um serviço e fazer alguma coisa dessas matérias, que eu não 
prestei atenção hoje possa cair amanhä, porque uma coisa simples, um número de matemática, uma palavra pode cair na prova que eu vou arrumar numa firma, coisa assim, pode cair isso (J.L.B., Aluno da Escola).

Quanto à direção e à coordenação, não foram consideradas ruins, apenas M. J. apontou que "as professoras é boa, a diretora não, a diretora é chata (risos), a diretora é folgada", porém considera a coordenadora "da hora", diferente de M. S., que diz "só a coordenadora e a diretora que é chata". Isto difere das opinióes ouvidas durante as Oficinas, quando a grande maioria dos alunos relatava que coordenação e especialmente a direção eram ruins, ainda que julgassem o fato de serem rígidas como algo bom.

J. foi o único que relatou algum tipo de discriminação na instituição, porém não voltado a ele e sim a outro aluno negro. Parece que o conceito de discriminação pode estar restrito a racismo e brincadeiras com colegas, visto que M.J. referiu que "a diretora sempre acha que é eu e os alunos não, quando eu estudava aqui sempre era eu que fazia bagunça e os alunos não". Pelo longo tempo de trabalho no local, sabemos que tal fato sucede igualmente com outros alunos, considerados mais indisciplinados, os "problemas da escola", e, por isso, são frequentemente culpabilizados por atitudes de outros e/ou coletivas ou recebem puniçốes exageradas se comparadas com a aplicada a alunos "não problemas".

Nenhum dos entrevistados admitiu não gostar de ir à escola. M. J. estava sem estudar há mais de sete meses, quando foi transferida, devido à indisciplina, para outra escola. No entanto, afirmava que só frequentaria as aulas naquela Escola (a deste estudo e onde nós a conhecemos) e que naquele momento estava disposta a assistir às aulas (uma das grandes reclamaçôes com relação a ela era pelo fato de ficar o tempo todo pelo pátio). Essa garota esteve longe dos estudos em outras ocasiōes, sempre por opção, e referiu que antes era por "preguiça, eu tinha preguiça, agora eu não tenho mais, mas agora não tem jeito". A aluna passava o período da manhá e parte do da tarde nos arredores da escola, chegando a entrar no prédio quando o portáo estava aberto, situaçóes em que era expulsa e ameaçada com a chamada da Ronda Escolar.

A escola, por sua vez, não foi considerada apta, por parte de outros entrevistados, para lidar com jovens em conflito com a lei. A presidente do Conselho Tutelar da cidade, afirmou que:

Ainda tem, eu acho que tem, muita discriminação, tem sim. E olha que tem várias alternativas, em 2004 e 2005 se fazia uma integração com os meninos das socioeducativas na escola. Tanto é que tem duas salas desse tipo [em uma escola privada da cidade], quinta e sexta série especiais. E olha, e por mais que você fale, que você vá lá, que a gente faça palestras, nós também fazemos palestras nas escolas, em entidades, e que você tente mudar essa mentalidade, é difícil, porque eles falam que a estrutura montada é realmente montada pra crianças que não trazem problemas (Representante do Conselho Tutelar da cidade).

Podemos concluir que, ainda que a instituição julgue estar preparada para atender a toda a demanda, seja ela qual for, o excerto da entrevista supracitada reflete melhor a realidade observada.

\subsection{O Estatuto da Criança e do Adolescente}

Com relação ao Estatuto da Criança e do Adolescente, temos, segundo a coordenadora, em entrevista concedida, um quadro em que:

\section{[...] a escola trabalhou muito em cima do ECA com as crianças logo que saiu e tem alguns professores que ainda leem pra eles, discutem com eles. [...] A nossa escola, por ser de periferia, a primeira coisa que nós fizemos foi fazer entre nossos professores um estudo do ECA, depois nós começamos a conversar com as crianças e ler algumas partes, os deveres, os direitos, porque eles acham que eles têm só direitos, eles não sabem dos deveres, e nós aqui já mostramos pra eles que eles têm direitos, mas têm um monte de deveres, $e$ eu acho que todas as escolas deveriam fazer o mesmo. Eu não sei se estão todas preparadas não (Coordenadora da Escola).}

Por outro lado, somente dois adolescentes referiram já ter ouvido falar sobre tal conjunto de leis, sem, contudo, conseguirem dizer do que se tratava. D. relatou ter ouvido sobre o ECA durante o cumprimento das medidas, embora não apresentasse uma opinião mais concreta sobre o tema.

É preocupante ouvir do próprio Secretário da Infância e Juventude da cidade colocaçôes como as que reproduzimos abaixo:

Os nossos professores estão muito despreparados, a nossa escola é uma escola excludente, ela, ao invés de abraçar o aluno ela joga o aluno pra fora, tá criando aí uma geração de analfabetos, então eu acho que assim, hoje é o descumprimento mais aviltante que existe ao Estatuto da Criança e do Adolescente infelizmente é a Educação, falando isso pelo menos no nivel do estado de São Paulo, 
mas eu acho que também de uma forma mais geral. Acho que ai [escola] o Estatuto ainda precisa realmente ser valorizado e ser aplicado (Secretário Municipal da Infância e Juventude).

Assim, percebe-se o quanto o Estatuto da Criança e do Adolescente (ECA) não está sendo trabalhado, náo é conhecido nem pelos alunos nem pelos professores, sendo que muitos pais e/ou responsáveis julgam, ainda, que tais leis atrapalham na boa educação dos filhos (conforme relato de alguns jovens e da direção da escola). O ECA longe de ser visto como um aliado, passa a ser considerado um empecilho à criação e à educação dos filhos. $\mathrm{O}$ representante do Conselho Municipal dos Direitos da Criança e do Adolescente traduz essa realidade ao afirmar que:

\section{[...] os professores não conhecem o Estatuto da Criança e do Adolescente, atuam com muito preconceito contra o Estatuto e deixam com isso de ter no Estatuto uma grande ferramenta que poderia ajudar tanto a reivindicar do poder público aquilo que é de direito do aluno, como deixam de usar também esta ferramenta pra cobrar do aluno aquilo que são seus deveres em relação à educação, à escola. Então, eu acho que a escola está muito distante, infelizmente, do Estatuto da Criança e do Adolescente (Representante do Conselho Municipal de Direitos da Criança e do Adolescente da cidade).}

Percebe-se também uma das consequências dessa resistência ao ECA: desconhecendo as leis, deveres e direitos dos jovens em situação de conflito com a lei, as atitudes voltadas a eles são, em grande parte das vezes, de impaciência e intolerância. São os jovens mais ameaçados de transferência, ainda que cheguem a ser vistos com 'pena' e/ou preocupação pelos professores. $\mathrm{O}$ fato desses adolescentes desconhecerem seus direitos leva às já citadas puniçóes exageradas e incongruentes. Concomitantemente, as próprias autoridades escolares não sabem como agir com eles e com todos os outros alunos, pois temem o Estatuto sem conhecê-lo e acham que qualquer atitude pode se voltar contra elas. Os resultados são um ECA desconhecido pela maioria e mal interpretado por quem sabe da sua existência, mas sem tê-lo compreendido efetivamente.

\subsection{As medidas socioeducativas}

Dentre os adolescentes entrevistados, apenas M. J. e M. S. não cumpriram uma medida socioeducativa; já os que a cumpriram, acreditavam que o Programa de Medidas Socioeducativas (PMSE) poderia ajudá-los de alguma forma e afirmaram que gostaram de frequentá-lo.

Além disso, duas adolescentes não terminaram de cumprir suas medidas socioeducativas, segundo elas, por preguiça de ir até o local dos atendimentos, no centro da cidade, distante do bairro onde residem. Desse modo, por náo terem cumprido a medida, à época da entrevista foram chamadas para nova audiência pela Vara da Infância e Juventude.

Quanto ao atendimento individual, foi citado como um dos fatores mais importantes e relevantes do PMSE. A alimentação que recebiam frequentando o local também era importante para eles, assim como as oficinas lá realizadas. Todavia, não conseguiram explicar bem o que faziam ou por que estavam no PMSE.

É surpreendente que, apesar dos problemas encontrados, das falhas e insuficiências institucionais, os jovens não tenham opiniāo formada sobre o sistema. Não esboçam uma visão crítica nem mesmo sendo os sujeitos das açóes incompletas ou mesmo das omissóes do poder público. De fato, nossa pesquisa mostra que náo foram apontadas críticas e as opinióes sobre o PMSE náo variam muito por parte dos adolescentes. Uma jovem relata que "bom, melhorou um pouco", ou seja, que frequentando o programa ela melhorou e modificou atitudes suas. Um menino mostrou-se entusiasmado com o PMSE e atribui ao seu cumprimento, além de à escola e às Oficinas de Atividades e Dinâmicas deste estudo, suas mudanças de comportamento.
Ah! eu achei super legal, tinha de tudo, tinha peça de teatro, a gente conversava, ele falava, eu falava a minha vida pessoal, o que eu queria, o que eu não queria, o que eu não gostava, $e$ tinha tudo, tinha aula de pintura, tinha tudo, tinha lanche lá se a gente ficasse com fome, tudo isso. [...], porque se não fosse vocês, a escola, o L. A. [Liberdade Assistida] eu acho que eu não seria a mesma pessoa que eu tô sendo hoje, agora (J. L. B., Aluno da Escola).

\section{Conclusão}

Com o trabalho nessa escola, pudemos notar o quanto seus professores e direçấo desconhecem a população com a qual trabalham. Todos os problemas que surgem com relação aos alunos são logo atribuídos à região onde a escola está inserida, o que parece justificá-los. Poucos profissionais relacionam as dificuldades cotidianas de seus alunos a outros fatores, como a administração do local e os próprios professores, por exemplo. Cria-se um circuito autorreferente que vincula bairro/pobreza/ violência ao aluno que está naquela escola, pobre/ 
violento/indisciplinado - fadado ao insucesso ou à exclusão social.

Alguns agentes escolares, segundo nossa pesquisa demonstrou, partilhavam da opiniáo de que jovens que passam (ou passaram) por programas de medidas socioeducativas não devem ser alvo de outras açôes socioeducativas, tais como as Oficinas de Atividades e Dinâmicas que realizávamos, de modo a não incentivar a indisciplina e também como uma forma de punição a eles.

A direção e a coordenação pedagógica da escola relataram a ausência de profissionais do Programa de Medidas Socioeducativas (PMSE) no trabalho de acompanhamento dos adolescentes. Dessa maneira, o artigo 119, inciso II, do Estatuto da Criança e do Adolescente, que garante ser responsabilidade do orientador do adolescente no PMSE "[...] supervisionar a frequência e o aproveitamento escolar do adolescente, promovendo, inclusive, sua matrícula." (BRASIL, 1990), não está sendo cumprido.

Além disso, temos um quadro em que o ECA está longe de ser cumprido dentro da escola, visto que é desconhecido. Muitas vezes, aqueles que deveriam conhecê-lo e aplicá-lo agem com preconceito, afastando-se ainda mais de tal instrumento.

Quanto à cidade de nosso estudo, seu programa de medidas socioeducativas é considerado modelo nacional. Sabemos das enormes dificuldades nacionais e, inclusive, no estado de Sáo Paulo, cujo maior "interlocutor" nesse campo até pouco tempo continuava sendo a FEBEM, atual Fundação CASA. Assim, um modelo depende das referências que estão postas. É preciso investigar melhor o alcance do que vem fazendo aquele programa, dimensionado não pelo que o Brasil não faz por seus adolescentes em conflito com a lei, mas sim pelo que os meninos e meninas que o frequentam pensam sobre o que estáo vivenciando e aprendendo como sujeitos de suas vidas e cidadãos que são.

Nesse sentido, a escola é uma referência fundamental para os adolescentes em geral, e para os de grupos populares em particular. Infelizmente, nela têm sido discriminados, mal vistos e, inúmeras vezes, expulsos, na maioria delas de forma velada por meio dos mecanismos da transferência compulsória. Se frequentar a escola tem importância fundamental e se torna obrigatória para o adolescente que cumpre medida socioeducativa, é ela que tem o dever de superar suas dificuldades para melhor acolhê-los e educá-los.

Através da atuação direta com os jovens, percebe-se que estấo insatisfeitos com a escola e, frequentemente, não constroem planos futuros, o que é extremamente preocupante. Não têm sonhos, projetos, perspectivas, e agem sem pensar nas possíveis consequências. Quedam-se em um vazio pessoal e social.

\section{Referências}

ABRAMO, H., BRANCO, P. P. M. Retratos da juventude brasileira: análise de uma pesquisa nacional. São Paulo: Fundaçáo Perseu Abramo; Instituto Cidadania, 2005.

ADORNO, S. A socialização incompleta: os jovens delinqüentes expulsos da escola. Cadernos de Pesquisa: revista de estudos e pesquisa em educacao / Fundacao Carlos Chagas, São Paulo, n. 79, p. 76-80, nov. 1991.

ARPINI, D. M. Violência e exclusão - adolescência em grupos populares. Bauru: Editora EDUSC, 2003.

BRASIL. Congresso Nacional. Constituição: República Federativa do Brasil. Brasília: Senado Federal; Centro Gráfico, 1988.

BRASIL. Ministério da Justiça. Secretaria de Estado dos Direitos Humanos. Departamento da Criança e do Adolescente - DCA. Conselho Nacional dos Direitos da Criança e do Adolescente - Conanda. Estatuto da criança e do adolescente. São Paulo: Cortez, 1990.

DULCE, B. (Org.). Cidadania e subjetividade: novos contornos e múltiplos sujeitos. São Paulo: Imaginário, 1997.

CASTEL, R. As metamorfoses da questão social: uma crônica do salário. 2. ed. Petrópolis: Vozes, 1999.

FREITAS, M. V.; PAPA, F. C. (Orgs.). Politicas públicas: juventude em pauta. São Paulo: Cortez; Ação Educativa; Fundação Friedrich Ebert, 2003.

GOHN, M. G. A formação da cidadania no Brasil através das lutas e movimentos sociais. Cidadanialtextos, Campinas, n. 1, p. 1-18, maio 1994.

LOPES, R. E. et al. Violência, escola e jovens de grupos populares urbanos: o caso de estudantes do ensino médio em São Carlos/SP. Revista HISTEDBR On-line, Campinas, n. 34, p. 73-96, 2009.

LOPES, R. E.; SILVA, C. R.; MALFITANO, A. P. S. Adolescência e juventude de grupos populares urbanos no Brasil e as políticas públicas: apontamentos históricos. Revista HISTEDBR On-line, Campinas, n. 23. p. 114-130, set. 2006 .

OFFE, C. Problemas estruturais do Estado capitalista. Rio de Janeiro: Tempo Brasileiro, 1984.

PILOTTI, F., RIZZINI, I. A arte de governar crianças: a história das políticas sociais, da legislação e da assistência à infância no Brasil. Rio de Janeiro: Instituto Interamericano Del Nino; Universidade Santa Úrsula; Amais, 1995.

REVISTA BRASILEIRA DE EDUCAÇÃO. Rio de Janeiro: ANPED, n. 5-6, maio/dez. 1997. Número especial: Juventude e contemporaneidade. Disponível em: <http://www.anped.org.br/RBDE056.pdf>. Acesso em: 15 dez. 2005.

SPOSITO, M. P.; CARRANO, M. C. R. Juventude e políticas públicas no Brasil. Revista Brasileira de Educação, Rio de Janeiro, n. 24, p. 16-39, set./dez. 2003. 


\section{Contribuição dos Autores}

Roseli Esquerdo Lopes: Concepção inicial do trabalho. Sara Caran Sfair: Coleta e organização dos dados. Roseli Esquerdo Lopes, Sara Caran Sfair e Marisa Bittar: Análise dos dados, elaboraçấo e redaçáo do texto.

\section{Notas}

${ }^{1}$ Este artigo é um dos desdobramentos do relatório da pesquisa "Adolescentes em Programas de Medidas Socioeducativas em Meio Aberto e a Escola”, desenvolvida com o apoio da Fundação de Amparo à Pesquisa do Estado de São Paulo FAPESP, integrando o projeto temático "Escola, Adolescência e Juventude em Grupos Populares: Cidadania, Direitos e Políticas Públicas”, coordenado pela Profa. Dra. Roseli Esquerdo Lopes, com financiamento do Conselho Nacional de Desenvolvimento Científico e Tecnológico - CNPq e do Ministério da Educação - MEC. Todos os procedimentos deste conjunto de pesquisas estiveram submetidos aos preceitos éticos necessários à sua realização.

2 Tomada como caso típico para uma gama importante de municípios médios no Brasil.

${ }_{3}^{3}$ Trata-se de uma escola que integra a rede pública da cidade e que é descrita adiante neste texto.

${ }^{4}$ Foram entrevistados: Juiz de Direito da Vara da Infância e Juventude; Representante do Conselho Municipal de Direitos da Criança e do Adolescente; Representante do Conselho Tutelar; Secretário Municipal da Infância e Juventude - Gestão 2005/2008; Direção, Coordenação e Professores da Escola Estadual onde a pesquisa foi realizada e Coordenação do Programa de Medidas Socioeducativas em Meio Aberto.

5 Transformada, em 2007, na Fundação CASA - Centro de Atendimento Socioeducativo ao Adolescente.

${ }^{6}$ Por até seis meses, o adolescente realizará tarefas gratuitas úteis à comunidade, segundo suas aptidôes, por no máximo oito horas semanais, sempre aos finais de semana e feriados, de modo que não atrapalhe a frequência à escola ou ao trabalho.

${ }^{7}$ Será fixada por no mínimo seis meses, podendo ser prorrogada, revogada ou substituída por outra medida. O orientador deve buscar reinserir o adolescente na sociedade, mesmo que através de programas oficiais/comunitários de auxílio e assistência social, supervisionar a frequência do jovem na escola e incentivar sua inserçâo no mercado de trabalho.

${ }^{8}$ Determinado desde o início ou como transição para meio aberto. Possibilita que o adolescente realize atividades externas, sendo obrigatória a escolarização e a profissionalização; não há prazo determinado.

${ }^{9}$ Permite a realização de atividades externas, a medida deve ser reavaliada a cada seis meses e aplicada para no máximo três anos, após o que passará para semiliberdade ou liberdade assistida e a liberação será compulsória aos 21 anos de idade. A internação deve ser em entidade exclusiva para adolescentes, na qual deverá realizar atividades pedagógicas; será aplicada apenas quando não houver outra medida adequada.

${ }^{10}$ Esse trabalho decorre de atividades de extensão universitária que permanecem em curso até o presente momento (2011).

${ }^{11}$ Professores que estiveram mais próximos das atividades desenvolvidas.

${ }^{12}$ Pela representação dos alunos em geral.

${ }^{13}$ Pela equipe gestora da escola e por acompanharem as atividades nas Oficinas

${ }^{14}$ Esse instrumento fez parte da pesquisa "Adolescentes e Jovens em Escolas Públicas de Ensino Médio na Cidade: Perfil Socioeconômico e Estudo Exploratório de sua Avaliação acerca da Violência na Escola” (LOPES et al., 2009). 